\title{
The Correlations among Depressive Symptoms, Cognitive Performance and Serum BDNF Levels in the Patients with Chronic Kidney Disease
}

\author{
Jung Goo Lee ${ }^{1,2,3 *}$, Min Kyung Park ${ }^{4 *}$, Yeong Hoon Kim ${ }^{5}$, Yang-Wook Kim \\ Kyubok $\mathrm{Jin}^{7}$, Sung Woo Park ${ }^{2,3,8}$, Mi Kyoung Seo², and Young Hoon $\mathrm{Kim}^{9} \bowtie$ \\ ${ }^{1}$ Department of Psychiatry, School of Medicine, Inje University Haeundae Paik Hospital, Busan, Republic of Korea \\ ${ }^{2}$ Paik Institute for Clinical Research, Inje University, Busan, Republic of Korea \\ ${ }^{3}$ Department of Health Science and Technology, Graduate School of Inje University, Busan, Republic of Korea \\ ${ }^{4}$ Department of Psychiatry, Jurye Jayeon Hospital, Busan, Republic of Korea \\ ${ }^{5}$ Department of Nephrology, School of Medicine, Inje University Busan Paik Hospital, Busan, Republic of Korea \\ ${ }^{6}$ Department of Medicine, School of Medicine, Inje University Haeundae Paik Hospital, Busan, Republic of Korea \\ ${ }^{7}$ Department of Medicine, Keimyung University Dongsan Medical Center, Daegu, Republic of Korea \\ ${ }^{8}$ Department of Convergence Biomedical Science, School of Medicine, Inje University, Busan, Republic of Korea \\ ${ }^{9}$ Department of Psychiatry, Gongju National Hospital, Gonju, Republic of Korea
}

Objective In the current study, we investigated whether there are relations among depressive symptoms, cognitive performance and serum BDNF levels in the patients with chronic kidney disease (CKD).

Methods Sixty patients with CKD and 65 healthy controls participated. Depressive symptoms were evaluated with Beck depression inventory (BDI) and Hamilton Depression Rating Scale (HDRS). Mini-Mental State Examination included in the Korean version of the Consortium to Establish a Registry for Alzheimer's disease (MMSE-KC) assessment packet was used for the evaluation of overall cognitive function. To assess memory function, the Korean version of the Hopkins Verbal Learning Test (K-HVLT) was used. BDNF levels were measured using an enzyme-linked immunosorbent assay (ELISA) kit.

Results The CKD patients showed more depressive symptoms when compared with controls. The depressive symptoms and cognitive function were not associated with serum BDNF levels in the CKD patients.

Conclusion In the current study, CKD patients had more depressive symptoms when compared controls. However, the serum BDNF levels of CKD patients were not associated with depressive symptoms and cognitive functions. These findings suggested that the serum BDNF levels may not be reflect the cognitive function and depressive mood state in the CKD patients.

Psychiatry Investig 2018;15(2):186-192

Key Words Chronic kidney disease, Depressive symptoms, Cognitive impairment, BDNF.

\section{INTRODUCTION}

Chronic kidney disease (CKD) is a serious medical condition with chronic course and may have dreadful end. ${ }^{1}$ Most

Received: November 8, 2016 Revised: February 18, 2017

Accepted: March 9, 2017 Available online: October 13, 2017

$\bowtie$ Correspondence: Young Hoon Kim, MD, PhD

Department of Psychiatry, Gongju National Hospital, 623-21 Gobunti-ro, Gongju 32601, Republic of Korea

Tel: +82-41-850-5700, Fax: +82-41-855-6969, E-mail: iybihwc@inje.ac.kr

*These authors contributed equally to this work.

(c) This is an Open Access article distributed under the terms of the Creative Commons Attribution Non-Commercial License (http://creativecommons.org/licenses/bync/4.0) which permits unrestricted non-commercial use, distribution, and reproduction in any medium, provided the original work is properly cited. of patients with CKD spend a large part of their lives receiving treatment, such as chronic ambulatory peritoneal dialysis, hemodialysis, or even kidney transplantation. ${ }^{2}$ CKD significantly impairs quality of life and also causes serious problems in mental health, interpersonal relationships, and social functioning. ${ }^{3,4}$ Recently, the concerns for mental health of CKD patients has grown and mental health has become one of the important treatment goals in CKD patients. ${ }^{4,5}$

It has been reported that major depressive disorder (MDD) is the most common mental illness in CKD patients. ${ }^{3,6}$ Although many CKD patients are suffering from depressive symptoms, proper diagnosis and treatment are usually not provided, and 
this may result in fatal outcomes such as suicide or cessation of CKD treatment. ${ }^{6-8}$ There have been studies for searching factors that may be related with MDD. ${ }^{9}$ In particular, it has been emphasized the brain-derived neurotrophic factor (BDNF) might play important role in the pathophysiology of MDD. ${ }^{10,11}$ BDNF is a neurotrophic factor that is essential for the survival and neuroplasticity of neurons. ${ }^{12,13}$ BDNF upregulates various neuroprotective proteins through the activation of mitogen-activated protein kinase (MAPK) signaling pathways. ${ }^{14}$ Although BDNF is produced primarily in the central nervous system, it is also secreted from the heart, lungs, kidneys, and spleen. ${ }^{15}$ In preclinical studies, it was reported that stress inhibited BDNF-mediated neurogenesis in the hippocampus, and decreased neurogenesis was restored by antidepressant administrations. ${ }^{12,16,17}$ In the studies with human subjects, reduced serum BDNF levels were observed in MDD patients. $^{18,19}$ The decreased hippocampal and forebrain volumes were observed and these changes in MDD patients are thought to reflect decreased levels of BDNF. ${ }^{20-22}$ Additionally, decreased levels of serum BDNF and BDNF mRNA were also observed in the MDD patients, and antidepressant treatment normalized these levels. ${ }^{23,24}$

Along with MDD or depressive symptoms, cognitive impairment is commonly observed in CKD patients. ${ }^{25,26}$ Uremic toxins in unfiltered blood may induce cognitive impairment and impaired cognitive function also can aggravate MDD or depressive symptoms in CKD patients. ${ }^{27,28}$ It has been also known that BDNF is associated with cognitive function. ${ }^{29}$ The associations between BDNF Val66Met genetic polymorphism and cognitive function were reported in the studies with human subjects. ${ }^{30,31}$ A number of studies revealed that BDNF influences cognitive function by affecting various factors associated with neural plasticity. ${ }^{32-34}$ Thus, it is apparent that BDNF plays a role in the pathophysiology of MDD or depressive symptoms and cognitive impairments. Thus, summarizing these findings, it can be postulated that a possible relation among depressive symptoms, cognitive impairment and serum BDNF might be existed. So, we wanted to find out whether there are possible relations among depressive symptoms, cognitive performance and serum BDNF levels in the patients with chronic kidney disease (CKD) in the current study.

\section{METHODS}

\section{Study subjects}

The subjects in the current study were walk-in patients diagnosed with CKD. A total of 60 patients with CKD participated in study. Selection criteria included 1) between the ages of 20 and 64 years and 2) a diagnosis of CKD lasting more than 3 months. Exclusion criteria included 1) inability to read and comprehend written consent, 2) comorbidity with other medical conditions, 3) currently receiving hemodialysis or peritoneal dialysis, because dialysis affects the levels of serum BDNF, and 4) Prior history of psychiatric illness. To minimize confounding effects, we did not recruit subjects with the comorbidities of psychiatric disorders and medical conditions. The control subjects were healthy individuals who voluntarily visited community health examination center. This study was conducted with the approval of the Institutional Review Boards of Inje University Haeundae Paik Hospital (2011-052) and Busan Paik Hospital (2011-096). All subjects fully understood about study and signed in written consents.

$\mathrm{CKD}$ was defined as the glomerular filtration rate (GFR) $<60 \mathrm{~mL} / \mathrm{min} / 1.73 \mathrm{~m}^{2}$ lasting for 3 months or longer. ${ }^{35,36} \mathrm{In}$ the current study, CKD is classified into five stages based on the degree of reduction in the GFR: GFR of $\geq 90 \mathrm{~mL} / \mathrm{min} / 1.73$ $\mathrm{m}^{2}$ (stage $1, \mathrm{n}=2$ ), GFR of $60-89 \mathrm{~mL} / \mathrm{min} / 1.73 \mathrm{~m}^{2}$ (stage $2, \mathrm{n}=$ 11), GFR of $30-59 \mathrm{~mL} / \mathrm{min} / 1.73 \mathrm{~m}^{2}$ (stage $3, \mathrm{n}=19$ ), GFR $15^{-}$ $29 \mathrm{~mL} / \mathrm{min} / 1.73 \mathrm{~m}^{2}$ (stage $4, \mathrm{n}=17$ ), and GFR $<15 \mathrm{~mL} / \mathrm{min} /$ $1.73 \mathrm{~m}^{2}$ (stage $5, \mathrm{n}=11$ ). ${ }^{36,37}$ We categorized stage $1-3$ patients as mild to moderate CKD group and stage $4-5$ patients as severe CKD group. ${ }^{36,38}$ We also categorized stage $1-2$ patients as early-stage group and stage 5 patients as end-stage group. ${ }^{36}$ The 60 patients with CKD were categorized according to these five stages based on these classification criteria.

\section{Data assessment}

\section{Assessment of depressive symptoms}

All subjects were interviewed and rated by psychiatrists. Standardized Korean version of Beck Depression Inventory (BDI) and Hamilton Depression Rating Scale (HDRS) were used for the evaluation of depressive symptoms $(8,9)$. Cut off scores of normal mood state for BDI is $<10$ and for HDRS is $<7.39,40$

\section{Evaluation of cognitive function}

There have been reported that Mini-Mental State Examination (MMSE) and Hopkins verbal learning test (HVLT) have relatively good sensitivity specificity for the screening of cognitive function and dementia. ${ }^{41-43}$ So we adapted MMSE and HVLT for the evaluation of cognitive function. The standardized Mini-Mental State Examination included in the Korean version of the Consortium to Establish a Registry for Alzheimer's disease (MMSE-KC) assessment packet and the Korean version of the Hopkins Verbal Learning Test (K-HVLT) were also used in the current study. ${ }^{44}$ The MMSE-KC, which has scores adjusted for respondents' age and educational level, consists of 19 items; the maximum score is 30 points. The K-HVLT, which consists of an immediate recall test, a de- 
layed recall test, and a recognition test. ${ }^{45}$ In the current study, we did recall test three times and the sum of recall test scores and the delayed recall test score were used as assessment data.

\section{Measurement of serum BDNF levels}

To measure serum BDNF levels, venous blood was drawn from the antecubital vein between 09:00 am and 11:00 am. We drew the venous blood in the collection tube without anticoagulant and then separated the serum in an Eppendorf tube using a centrifuge $\left(3,000 \mathrm{rpm}, 10 \mathrm{~min}, 4^{\circ} \mathrm{C}\right)$. The serum was stored at $-70^{\circ} \mathrm{C}$ until BDNF analysis. BDNF levels were measured using an enzyme-linked immunosorbent assay (ELISA) kit (Promega, Madison, WI, USA). ${ }^{46}$

\section{Statistical analysis}

The analysis of demographic data and one-way analysis of variance (ANOVA) followed by Sidak's multiple comparisons test was performed using Graphpad Prism version 7.01 for Windows, GraphPad Software, La Jolla California USA, www. graphpad.com. Associations among BDI, HDRS, MMSE-KC, and K-HVLT scores and serum BDNF levels were evaluated using the Spearman correlation test. The level of statistical significance was set at a $\mathrm{p}$-value $<0.05$.

\section{RESULTS}

\section{Demographic characteristics of subjects}

Sixty CKD patients and 65 healthy control participated in this study. 25 subjects in the CKD group (29.41\%) and 29 in the control group (44.62\%) were female gender. The average age of the CKD group was $50.53 \pm 10.43$ years, and that of the control group was $48.03 \pm 9.35$ years. We found that there were no statistically significant differences between the two groups in age and gender distributions (Table 1).

\section{Depressive symptoms in the CKD group}

The BDI total scores were significantly higher in the CKD group than in the control group ( $\mathrm{p}<0.05)$, and the HDRS total scores were also significantly higher in the CKD group than in the control group $(\mathrm{p}<0.05)$ (Table 1$)$. However, the results of multiple regression analysis with covariates (age and female) revealed that there were no statistically differences in the BDI scores and the HDRS scores. When the CKD patients were divided into groups of those with mild to moderate (stage 1-3) and severe (stage 4-5) CKD, the BDI scores of those in the severe $\mathrm{CKD}$ group $(\mathrm{p}<0.05)$ were significantly higher than were those in the control group, whereas the HDRS scores of both the mild to moderate and severe CKD groups were significantly higher than were those of the control group $(\mathrm{p}<0.05)$. Additionally, the proportion of subjects with BDI scores of $\geq 10$ and subjects with HDRS scores of $\geq 7$ were significantly greater in the CKD group than in the control group $(\mathrm{p}<0.05)$ (Table 2).

\section{Cognitive function in the CKD group}

Overall cognitive function as assessed by MMSE-KC was not significantly different among groups. However, there was statistically difference in the results of multiple analysis with covariates (age and female) $(\mathrm{p}=0.048)$ (Table 1). When verbal memory was assessed using the K-HVLT, the CKD group showed significantly lower scores on the recall test $(\mathrm{p}<0.05)$ and a tendency toward lower scores on the delayed recall test $(\mathrm{p}<0.063)$ compared with the control group (Table 1$)$. The results of multiple regression analysis with covariates (age and female) showed that there were statistically differences in immediate recall test scores and delayed recall test scores between the CKD group and the BDNF group $(\mathrm{p}<0.05)$ (Table 1$)$. When the $\mathrm{CKD}$ group was divided into the mild to moderate $\mathrm{CKD}$ (stage 1-3) and the severe CKD (stage 4-5) groups, there were

Table 1. Demographic characteristics of subjects

\begin{tabular}{|c|c|c|c|c|}
\hline & Control $(\mathrm{N}=65)$ & $\mathrm{CKD}(\mathrm{N}=60)$ & $\begin{array}{c}\text { ANOVA } \\
\text { p value (adjusted) }\end{array}$ & $\begin{array}{c}\text { ANCOVA } \\
\text { p value }\end{array}$ \\
\hline Age, mean (SD) years & $48.03(9.35)$ & $50.53(10.43)$ & $>0.05$ & \\
\hline Female, N (\%) & $29(44.62)$ & $25(29.41)$ & $>0.05^{*}$ & \\
\hline MMSE-KC, mean (SD) & $27.7(1.75)$ & $27.32(2.39)$ & $>0.05$ & $<0.05$ \\
\hline HVLT-I, mean (SD) & $23.09(5.73)$ & $20.72(5.09)$ & $<0.05$ & $<0.05$ \\
\hline HVLT-D, mean (SD) & $8.00(2.76)$ & $7.15(2.56)$ & $>0.05$ & $<0.05$ \\
\hline BDI, mean (SD) & $6.45(6.13)$ & $8.62(6.00)$ & $<0.05$ & $>0.05$ \\
\hline HDRS, mean (SD) & $3.59(3.04)$ & $5.85(4.13)$ & $<0.05$ & $>0.05$ \\
\hline BDNF, mean (SD) & $11.23(1.18)$ & $11.06(1.07)$ & $>0.05$ & $>0.05$ \\
\hline
\end{tabular}

Different superscripts indicate significant differences according to Sidak's multiple comparisons test $(\mathrm{p}<0.05)$. ANCOVA significance for the covariate (age, female) is presented in the $4^{\text {th }}$ column. ${ }^{*}$ Fisher's exact test, p value was not adjusted. BDI: Beck Depression Inventory, BDNF: Brain-Derived Neurotrophic Factor, CKD: Chronic Kidney disease, HDRS: Hamilton Depression Rating Scale, MMSE-KC: Mini-Mental State Examination included in the Korean version of the Consortium to Establish a Registry for Alzheimer's disease assessment packet was used for the evaluation of overall cognitive function, To assess memory, HVLT-I: Korean version of the Hopkins Verbal Learning Test immediate recall, HVLT-D: Korean version of the Hopkins Verbal Learning Test delayed recall, ANOVA: analysis of variance, ANCOVA: analysis of covariance 
no significant differences in MMSE-KC scores, immediate recall test scores and delayed recall test scores among the mild to moderate CKD group, the severe CKD group and the control group (Table 3).

\section{Serum BDNF levels in the CKD group}

The serum BDNF level was $11.23 \pm 1.18 \mathrm{ng} / \mathrm{mL}$ in the 65 healthy controls and $11.06 \pm 1.07 \mathrm{ng} / \mathrm{mL}$ in the 60 patients with $\mathrm{CKD}$ and there was no significant difference between the two groups (Table 1). Additionally, the serum BDNF levels were significantly lower in the end-stage (stage 5 ) group than in the early-stage (stages 1-2) group $(\mathrm{p}<0.05)$.

\section{Correlations among depressive symptoms, cognitive functioning, and serum BDNF levels}

There were negative correlations between age and MMSE$\mathrm{KC}$, recall test scores and delayed recall test scores $(\mathrm{p}<0.05)$. BDI scores showed statistically significant positive correlations with HDRS scores, MMSE-KC scores and delayed recall test scores $(\mathrm{p}<0.05)$. Additionally, HDRS scores also showed statistically significant positive correlations with BDI scores $(\mathrm{p}<$
0.05). However, serum BDNF levels in the CKD group were not significantly associated with MMSE-KC scores, K-HVLT recall test scores, BDI and HDRS scores (Table 4). In the current study, it appears that neither depressive symptoms nor cognitive impairments were associated with serum BDNF levels in the CKD group.

\section{DISCUSSION}

In the current study, we observed that CKD patients have more depressive symptoms when compared with controls. However, serum BDNF levels were not associated with depressive symptoms or cognitive decline in CKD patients.

MDD is a common mental illness among the CKD patients. ${ }^{3,6}$ Although the reported prevalence varies greatly across studies, about $20-30 \%$ of CKD patients could be diagnosed as MDD. ${ }^{47}$ Comparing with the lifetime prevalence of MDD in the general population, the prevalence among CKD patients is considerably high. ${ }^{3,6,47}$ It has been also known that MDD could aggravate the medical condition of $\mathrm{CKD}$ by impairing the immune and hormone systems. ${ }^{48}$ Thus, early detection and

Table 2. Comparisons of BDI and HDRS total scores between control and CKD groups

\begin{tabular}{|c|c|c|c|c|}
\hline & \multirow{2}{*}{ Controls $(\mathrm{N}=65)$} & \multicolumn{2}{|c|}{ CKD patients } & \multirow[b]{2}{*}{$\mathrm{p}$} \\
\hline & & Stage $1-3(\mathrm{~N}=32)$ & Stage $4-5(N=28)$ & \\
\hline BDI total score (\% above 10$)$ & $14(21.5)$ & $11(34.3)$ & $15(53.6)$ & $<0.05$ \\
\hline HDRS total score (\% above 7 ) & $10(15.4)$ & $10(31.3)$ & $11(39.3)$ & $<0.05$ \\
\hline
\end{tabular}

BDI: Beck depression inventory, CKD: Chronic Kidney Disease, HDRS: Hamilton Depression Rating Scale

Table 3. Comparisons of HVLT-I and HVLT-D total scores between control and CKD groups

\begin{tabular}{|c|c|c|c|c|}
\hline & \multirow{2}{*}{ Controls $(\mathrm{N}=65)$} & \multicolumn{2}{|c|}{ CKD patients } & \multirow{2}{*}{$\mathrm{p}$} \\
\hline & & Stage $1-3(N=32)$ & Stage $4-5(N=28)$ & \\
\hline MMSE-KC, mean(SD) & $27.70(1.75)$ & $27.76(2.43)$ & $27.00(2.56)$ & $>0.05$ \\
\hline HVLT-I, mean(SD) & $23.09(5.73)$ & $21.19(4.65)$ & $20.75(6.40)$ & $>0.05$ \\
\hline HVLT-D, mean(SD) & $8.00(2.76)$ & $7.24(0.91)$ & $7.18(2.60)$ & $>0.05$ \\
\hline
\end{tabular}

CKD: Chronic Kidney Disease, HVLT-I: Korean version of the Hopkins Verbal Learning Test immediate recall, HVLT-D: Korean version of the Hopkins Verbal Learning Test delayed recall

Table 4. Correlation matrices between clinical data and serum BDNF levels in the CKD group

\begin{tabular}{|c|c|c|c|c|c|c|c|}
\hline & Age & BDNF & $\mathrm{BDI}$ & HDRS & MMSE-KC & HVLT-I & HVLT-D \\
\hline Age & & -0.105 & 0.102 & -0.007 & -0.453 & $-0.480^{*}$ & $-0.536^{*}$ \\
\hline BDNF & -0.105 & & -0.043 & 0.082 & -0.104 & -0.211 & -0.105 \\
\hline BDI & 0.102 & -0.043 & & $0.694^{*}$ & -0.265 & -0.238 & $-0.306^{*}$ \\
\hline HDRS & -0.007 & 0.082 & $0.694^{*}$ & & -0.254 & -0.198 & -0.263 \\
\hline MMSE-KC & $-0.453^{*}$ & -0.104 & $-0.265^{*}$ & -0.254 & & $0.574^{*}$ & $0.544^{*}$ \\
\hline HVLT-I & $-0.480^{*}$ & -0.211 & -0.238 & -0.198 & $0.574^{*}$ & & $0.819^{*}$ \\
\hline HVLT-D & $-0.536^{*}$ & -0.105 & $-0.306^{*}$ & -0.263 & $0.544^{*}$ & $0.819^{*}$ & \\
\hline
\end{tabular}

Spearman correlation. *marked correlations are significant at $\mathrm{p}<0.05$. BDI: Beck depression inventory, BDNF: Brain-Derived Neurotrophic Factor, CKD: Chronic Kidney Disease, HDRS: Hamilton Depression Rating Scale, MMSE-KC: Mini-Mental State Examination included in the Korean version of the Consortium to Establish a Registry for Alzheimer's disease assessment packet was used for the evaluation of overall cognitive function, To assess memory, HVLT-I: Korean version of the Hopkins Verbal Learning Test immediate recall, HVLT-D: Korean version of the Hopkins Verbal Learning Test delayed recall 
proper treatment of MDD among CKD patients are necessary.

For the detection of MDD, assessment tools such as BDI and HDRS are widely used in clinical settings. ${ }^{49} \mathrm{BDI}$ is easy to use due to its self-report format, and HDRS has the advantage of adding a clinician's objective assessment. ${ }^{50,51}$ In the current study, BDI and HDRS were used to quantitatively evaluate MDD in CKD patients, and the CKD group was found to have more severe depressive symptoms than the control group. Among CKD patients, the proportion of patients with HDRS scores $\geq 7$ was $35.0 \%$, which was significantly higher than the $15.4 \%$ found in the control group. Additionally, the proportion of CKD patients with BDI scores $\geq 10$ was greater that it was in the control group ( $43.3 \%$ vs. $21.5 \%$ ). These findings are consistent with results of previous studies in which the prevalence of MDD was found to be higher among CKD patients than in the general population. ${ }^{3,4,6}$

The current study measured serum BDNF levels in the control group as well as in the CKD group. It has been known that BDNF may play an important role in the pathogenesis of MDD., 90,31 The "BDNF hypothesis" of MDD is based on the fact that stress reduce BDNF expression in the hippocampus and that antidepressants can restore BDNF levels. ${ }^{9,52,53}$

In previous studies, decreased the levels of BDNF in the hippocampus and in plasma of the patients with MDD were observed. ${ }^{54}$ In the studies with CKD patients, it has been reported that female gender is associated with the lower levels of plasma BDNF. ${ }^{55}$ Kielstein et al. ${ }^{56}$ also reported inverse relationship of BDNF and BDI in chronic hemodialysis patients. However, there were no difference in the BDNF levels between the CKD group and the control group in the current study. Correlation analysis also revealed that there were no correlations between serum BDNF levels and MMSE-KC scores, recall scores, delayed recall scores, BDI scores and HDRS scores. Only the levels of serum BDNF in CKD patients stage 5 were significantly lower than the those of CKD stage 1-2 (data were not shown). It is difficult to estimate with these results alone whether low serum BDNF levels in end-stage CKD patients may be caused by chronic stress or as a result of a hypothalamic-pituitary axis dysfunction. ${ }^{57}$ Summarizing these findings, serum BDNF levels measured in the current study were also not associated with scores on clinical rating scales that quantitatively measure depressive symptoms. That is, we were unable to verify the relations between BDNF and depressive symptoms in the current study. The reason for this failure may be due to the scales used in this study. It has been a controversy regarding whether clinical rating scales are suitable for assessing MDD in CKD patients exists. Because the items of BDI and HDRS scales include physical symptoms that patients with CKD may complain regardless of MDD. ${ }^{49}$

CKD patients may have functional impairment in the cen- tral nervous system because they cannot eliminate uremic toxins that are generated in the body, which could result in cognitive impairment. ${ }^{58}$ Cognitive impairment among CKD patients is commonly observed in clinical settings. A previous study reported abnormal digit symbol substitution scores and modified stroop color word scores in CKD patients. ${ }^{59}$ In the current study, overall cognitive function as assessed by the MMSE-KC was not significantly different between the CKD patients and controls. However, the results of multiple regressive analysis with covariates (age and female) revealed that there were statistically differences in MMSE-KC scores, HVLT-I and VHLT-D scores between the CKD and the control group. Additionally, serum BDNF levels did not have a significant association with scores on the depression rating scale or the degree of cognitive functioning among CKD patients. Therefore, it may be inferred that the impairment of cognitive functioning in CKD patients may not be associated with BDNF levels in the current study. ${ }^{60,61}$

The limitations of this study are as follows. First, the number of CKD patients was small, making it impossible to create sufficiently large groups representing various degrees of renal function impairment. Because cognitive function and serum BDNF levels can vary with the degree of renal function impairment, studies with enough subjects will be needed. Second, we did not use the structured interview for the screening the mental states of the CKD and normal groups. The current study was a cross sectional design and the depressive scores were presentation of the current mood state of CKD patients. So, the structured interview to screen the mental state of subjects should be necessary. Third, the use of drugs and other multiple factors that might influence the serum BDNF levels and cognitive function in CKD patients were not controlled. Thus, further studies will be necessary to obtain more meaningful results if they are able to control for these factors.

In the current study, CKD patients showed more depressive symptoms when compared with controls. The depressive symptoms and cognitive functioning were not associated with serum BDNF levels among CKD patients. In other words, we could not verify BDNF involvement in the development of depression and cognitive impairment.

\section{REFERENCES}

1. Eggers PW. Has the incidence of end-stage renal disease in the USA and other countries stabilized? Curr Opin Nephrol Hypertens 2011;20: 241-245.

2. McClellan AC, Plantinga L, McClellan WM. Epidemiology, geography and chronic kidney disease. Curr Opin Nephrol Hypertens 2012;21: 323-328.

3. Palmer S, Vecchio M, Craig JC, Tonelli M, Johnson DW, Nicolucci A, et al. Prevalence of depression in chronic kidney disease: systematic review and meta-analysis of observational studies. Kidney Int 2013;84: 179-191. 
4. Ricardo AC, Fischer MJ, Peck A, Turyk M, Lash JP. Depressive symptoms and chronic kidney disease: results from the National Health and Nutrition Examination Survey (NHANES) 2005-2006. Int Urol Nephro. 2010;42:1063-1068.

5. Link DK, Saxena R. The right patient, the right treatment, the right access and the right time. Adv Chronic Kidney Dis 2014;21:360-364.

6. Hedayati SS, Finkelstein FO. Epidemiology, diagnosis, and management of depression in patients with CKD. Am J Kidney Dis 2009;54: 741-752.

7. Wang PL, Watnick SG. Depression: a common but underrecognized condition associated with end-stage renal disease. Semin Dial 2004;17: 237-241.

8. Cukor D, Peterson RA, Cohen SD, Kimmel PL. Depression in endstage renal disease hemodialysis patients. Nat Clin Pract Nephrol 2006; 2:678-687.

9. Krishnan V, Nestler EJ. The molecular neurobiology of depression. Nature 2008;455:894-902.

10. Hashimoto K. Brain-derived neurotrophic factor as a biomarker for mood disorders: an historical overview and future directions. Psychiatry Clin Neurosci 2010;64:341-357.

11. Hashimoto K, Shimizu E, Iyo M. Critical role of brain-derived neurotrophic factor in mood disorders. Brain Res Brain Res Rev 2004;45:104114.

12. Duman RS, Monteggia LM. A neurotrophic model for stress-related mood disorders. Biol Psychiatry 2006;59:1116-1127.

13. Castren E, Rantamaki T. Neurotrophins in depression and antidepressant effects. Novartis Found Symp 2008;289:43-52.

14. Numakawa T, Suzuki S, Kumamaru E, Adachi N, Richards M, Kunugi H. BDNF function and intracellular signaling in neurons. Histol Histopathol 2010;25:237-258.

15. Yang ZF, Ho DW, Lam CT, Luk JM, Lum CT, Yu WC, et al. Identification of brain-derived neurotrophic factor as a novel functional protein in hepatocellular carcinoma. Cancer Res 2005;65:219-225.

16. Schmidt HD, Duman RS. The role of neurotrophic factors in adult hippocampal neurogenesis, antidepressant treatments and animal models of depressive-like behavior. Behav Pharmacol 2007;18:391-418.

17. Masi G, Brovedani P. The hippocampus, neurotrophic factors and depression: possible implications for the pharmacotherapy of depression. CNS Drugs 2011;25:913-931.

18. Karege F, Perret G, Bondolfi G, Schwald M, Bertschy G, Aubry JM. Decreased serum brain-derived neurotrophic factor levels in major depressed patients. Psychiatry Res 2002;109:143-148.

19. Yoshimura R, Umene-Nakano W, Hoshuyama T, Ikenouchi-Sugita A, Hori $\mathrm{H}$, Katsuki A, et al. Plasma levels of brain-derived neurotrophic factor and interleukin- 6 in patients with dysthymic disorder: comparison with age- and sex-matched major depressed patients and healthy controls. Hum Psychopharmacol 2010;25:566-569.

20. Kanellopoulos D, Gunning FM, Morimoto SS, Hoptman MJ, Murphy $\mathrm{CF}$, Kelly RE, et al. Hippocampal volumes and the brain-derived neurotrophic factor val66met polymorphism in geriatric major depression. Am J Geriatr Psychiatry 2011;19:13-22.

21. Frodl T, Schule C, Schmitt G, Born C, Baghai T, Zill P, et al. Association of the brain-derived neurotrophic factor Val66Met polymorphism with reduced hippocampal volumes in major depression. Arch Gen Psychiatry 2007;64:410-416.

22. Harrisberger F, Smieskova R, Schmidt A, Lenz C, Walter A, Wittfeld K, et al. BDNF Val66Met polymorphism and hippocampal volume in neuropsychiatric disorders: a systematic review and meta-analysis. Neurosci Biobehav Rev 2015;55:107-118.

23. Serra-Millas M, Lopez-Vilchez I, Navarro V, Galan AM, Escolar G, Penades R, et al. Changes in plasma and platelet BDNF levels induced by S-citalopram in major depression. Psychopharmacology (Berl) 2011; 216:1-8.

24. Cattaneo A, Bocchio-Chiavetto L, Zanardini R, Milanesi E, Placentino A, Gennarelli M. Reduced peripheral brain-derived neurotrophic fac- tor mRNA levels are normalized by antidepressant treatment. Int J Neuropsychopharmacol 2010;13:103-108.

25. Etgen T, Chonchol M, Forstl H, Sander D. Chronic kidney disease and cognitive impairment: a systematic review and meta-analysis. Am J Nephrol 2012;35:474-482.

26. Elias MF, Dore GA, Davey A. Kidney disease and cognitive function. Contrib Nephrol 2013;179:42-57.

27. Sanchez-Roman S, Ostrosky-Solis F, Morales-Buenrostro LE, NoguesVizcaino MG, Alberu J, McClintock SM. Neurocognitive profile of an adult sample with chronic kidney disease. J Int Neuropsychol Soc 2011; 17:80-90.

28. Radic J, Ljutic D, Radic M, Kovacic V, Sain M, Curkovic KD. The possible impact of dialysis modality on cognitive function in chronic dialysis patients. Neth J Med 2010;68:153-157.

29. Bekinschtein P, Cammarota M, Medina JH. BDNF and memory processing. Neuropharmacology 2014;76:677-683.

30. Voineskos AN, Lerch JP, Felsky D, Shaikh S, Rajji TK, Miranda D, et al. The brain-derived neurotrophic factor Val66Met polymorphism and prediction of neural risk for Alzheimer disease. Arch Gen Psychiatry 2011;68:198-206.

31. Montag C, Weber B, Fliessbach K, Elger C, Reuter M. The BDNF Val$66 \mathrm{Met}$ polymorphism impacts parahippocampal and amygdala volume in healthy humans: incremental support for a genetic risk factor for depression. Psychol Med 2009;39:1831-1839.

32. Schofield PR, Williams LM, Paul RH, Gatt JM, Brown K, Luty A, et al. Disturbances in selective information processing associated with the BDNF Val66Met polymorphism: evidence from cognition, the P300 and fronto-hippocampal systems. Biol Psychol 2009; 80:176-188.

33. Blurton-Jones M, Kitazawa M, Martinez-Coria H, Castello NA, Muller FJ, Loring JF, et al. Neural stem cells improve cognition via BDNF in a transgenic model of Alzheimer disease. Proc Natl Acad Sci U S A 2009; 106:13594-13599.

34. Juhasz G, Dunham JS, McKie S, Thomas E, Downey D, Chase D, et al. The CREB1-BDNF-NTRK2 pathway in depression: multiple gene-cognition-environment interactions. Biol Psychiatry 2011;69:762-771.

35. Zoladz JA, Smigielski M, Majerczak J, Nowak LR, Zapart-Bukowska J, Smolenski O, et al. Hemodialysis decreases serum brain-derived neurotrophic factor concentration in humans. Neurochem Res 2012;37:27152724.

36. Levey AS, Coresh J. Chronic kidney disease. Lancet 2012;379:165-180.

37. Levey AS, Coresh J, Balk E, Kausz AT, Levin A, Steffes MW, et al. National Kidney Foundation practice guidelines for chronic kidney disease: evaluation, classification, and stratification. Ann Intern Med 2003; 139:137-147.

38. Levey AS, de Jong PE, Coresh J, El Nahas M, Astor BC, Matsushita K, et al. The definition, classification, and prognosis of chronic kidney disease: a KDIGO Controversies Conference report. Kidney Int 2011;80: $17-28$.

39. Hahn H, Yum T, Shin Y, Kim Y, Yoon D, Chung K. A standardization study of Beck Depression Inventory in Korea. J Korean Neuropsychiatr Assoc 1986;25:487-500.

40. Yi J, Bae S, Ahn Y, Park D, Noh K, Shin H, et al. Validity and Reliability of the Korean version of the Hamilton Depression Rating Scale (KHDRS). J Korean Neuropsychiatr Assoc 2005;44:456-465.

41. Kuslansky G, Katz M, Verghese J, Hall CB, Lapuerta P, LaRuffa G, et al. Detecting dementia with the Hopkins Verbal Learning Test and the Mini-Mental State Examination. Arch Clin Neuropsychol. 2004;19:89104.

42. Lacy M, Kaemmerer T, Czipri S. Standardized mini-mental state examination scores and verbal memory performance at a memory center: implications for cognitive screening. Am J Alzheimers Dis Other Demen 2015;30:145-152.

43. Xu X, Xiao S, Rahardjo TB, Hogervorst E. Risk Factors for Possible Dementia Using the Hopkins Verbal Learning Test and the Mini-Mental State Examination in Shanghai. Diagnostics (Basel) 2015;5:487-496. 
44. Lee JH, Lee KU, Lee DY, Kim KW, Jhoo JH, Kim JH, et al. Development of the Korean version of the Consortium to Establish a Registry for Alzheimer's Disease Assessment Packet (CERAD-K): clinical and neuropsychological assessment batteries. J Gerontol B Psychol Sci Soc Sci 2002;57:47-53.

45. Baek MJ, Kim HJ, Ryu HJ, Lee SH, Han SH, Na HR, et al. The usefulness of the story recall test in patients with mild cognitive impairment and Alzheimer's disease. Neuropsychol Dev Cogn B Aging Neuropsychol Cogn 2011;18:214-229.

46. Lee JG, Shin BS, You YS, Kim JE, Yoon SW, Jeon DW, et al. Decreased serum brain-derived neurotrophic factor levels in elderly korean with dementia. Psychiatry Investig 2009;6:299-305.

47. Tossani E, Cassano P, Fava M. Depression and renal disease. Semin Dial 2005;18:73-81

48. Kimmel PL. Depression in patients with chronic renal disease: what we know and what we need to know. J Psychosom Res 2002;53:951-956.

49. Hedayati SS, Bosworth HB, Kuchibhatla M, Kimmel PL, Szczech LA. The predictive value of self-report scales compared with physician diagnosis of depression in hemodialysis patients. Kidney Int 2006;69:16621668.

50. Nuevo R, Lehtinen V, Reyna-Liberato PM, Ayuso-Mateos JL. Usefulness of the Beck Depression Inventory as a screening method for depression among the general population of Finland. Scand J Public Health 2009; 37:28-34.

51. Satthapisit S, Posayaanuwat N, Sasaluksananont C, Kaewpornsawan T, Singhakun S. The comparison of Montgomery and Asberg Depression Rating Scale (MADRS thai) to diagnostic and statistical manual of mental disorders (DSM) and to Hamilton Rating Scale for Depression (HRSD): validity and reliability. J Med Assoc Thai 2007;90:524-531.

52. Nestler EJ, Barrot M, DiLeone RJ, Eisch AJ, Gold SJ, Monteggia LM. Neurobiology of depression. Neuron 2002;34:13-25.
53. Drevets WC. Neuroimaging and neuropathological studies of depression: implications for the cognitive-emotional features of mood disorders. Curr Opin Neurobiol 2001;11:240-249.

54. Kempermann G. The neurogenic reserve hypothesis: what is adult hippocampal neurogenesis good for? Trends Neurosci 2008;31:163-169.

55. Marchelek-Mysliwiec M, Cichocka E, Dziedziejko V, Dutkiewicz GZ, Stepniewska J, Safranow K, et al. Insulin resistance and brain-derived neurotrophic factor levels in chronic kidney disease. Ann Clin Biochem 2015;52:213-219.

56. Kielstein H, Suntharalingam M, Perthel R, Song R, Schneider SM, Martens-Lobenhoffer J, et al. Role of the endogenous nitric oxide inhibitor asymmetric dimethylarginine (ADMA) and brain-derived neurotrophic factor (BDNF) in depression and behavioural changes: clinical and preclinical data in chronic kidney disease. Nephrol Dial Transplant 2015; 30:1699-1705.

57. Meuwese CL, Carrero JJ. Chronic kidney disease and hypothalamic-pituitary axis dysfunction: the chicken or the egg? Arch Med Res 2013;44: 591-600.

58. Watanabe K, Watanabe T, Nakayama M. Cerebro-renal interactions: impact of uremic toxins on cognitive function. Neurotoxicology 2014; 44:184-193.

59. Umemura T, Kawamura T, Umegaki H, Kawano N, Mashita S, Sakakibara $\mathrm{T}$, et al. Association of chronic kidney disease and cerebral small vessel disease with cognitive impairment in elderly patients with type 2 diabetes. Dement Geriatr Cogn Dis Extra 2013;3:212-222.

60. McIntyre RS, Lee Y. Cognition in major depressive disorder: a 'Systemically Important Functional Index' (SIFI). Curr Opin Psychiatry 2016;29:48-55.

61. MacQueen GM, Memedovich KA. Cognitive dysfunction in major depression and bipolar disorder: assessment and treatment options. Psychiatry Clin Neurosci 2017;71:18-27. 